\title{
Determinants of modern contraceptive use among married Somali women living in Kampala; a cross sectional survey
}

Maryan Abdulahi, Othman Kakaire and Fatuma Namusoke*

\begin{abstract}
Background: Low contraceptive uptake exposes women to unintended pregnancies and often the resultant obstetric complications. The immigrant communities especially from countries with low contraceptive use present a unique challenge. The main objective of the study was to describe modern contraceptive use and associated factors among married Somali women living in Kampala.

Methods: A community based cross sectional survey was conducted among Somali women living in Kampala from August to November 2016. Using consecutive sampling, 341 respondents were recruited after informed consent. Data was collected using interviewer administered questionnaires on contraceptives use and factors associated. Data was entered in Epidata 3.1 and analyzed using STATA 11.0. Logistic regression analysis was used to determine the factors associated with use of modern contraceptives.

Results: Majority of the participants were refugees 317/341(94\%), with a mean age of $30.4( \pm 6.7)$ years and 136/341 (40\%) had no formal education. More than 325/341 (95\%) of respondents desired to have five or more children (Average $9 \pm 3$ ) and 164/341 (45\%) had five or more living children. Only 29\% of women were using modern contraceptives, of which $51 \%$ used oral pills, $15 \%$ condoms and 15\% injectables. Having tertiary education, one who had ever used modern contraceptives and desire for spacing of more than two years were independently associated with current of use modern contraceptives.

Conclusions: The Contraceptive prevalence rate among married Somali women in Kampala was (29\%). A majority of the respondents were using short acting contraceptive methods. Attaining tertiary education, ever use of modern contraceptives, those whose source of contraceptive information was health worker and desire to space for more than two years were associated with current use of modern contraceptives. There is a need for improvement of girl child education, contraceptive awareness and male involvement to increase contraceptive uptake in this community. Research looking at attitude of this community towards use of long term contraception is recommended.
\end{abstract}

Keywords: Modern contraceptives use, Somali women, Kampala

\footnotetext{
* Correspondence: namusokefk@yahoo.co.uk

Department of Obstetrics and Gynaecology, School of Medicine, Makerere

University, 7062, Kampala, Uganda
}

C C The Author(s). 2020 Open Access This article is licensed under a Creative Commons Attribution 4.0 International License, which permits use, sharing, adaptation, distribution and reproduction in any medium or format, as long as you give appropriate credit to the original author(s) and the source, provide a link to the Creative Commons licence, and indicate if changes were made. The images or other third party material in this article are included in the article's Creative Commons licence, unless indicated otherwise in a credit line to the material. If material is not included in the article's Creative Commons licence and your intended use is not permitted by statutory regulation or exceeds the permitted use, you will need to obtain permission directly from the copyright holder. To view a copy of this licence, visit http://creativecommons.org/licenses/by/4.0/. The Creative Commons Public Domain Dedication waiver (http://creativecommons.org/publicdomain/zero/1.0/) applies to the data made available in this article, unless otherwise stated in a credit line to the data. 


\section{Plain English summary}

Low utilization of modern contraceptives among married couples leads to unwanted pregnancy which is associated with an increase in maternal morbidity and mortality. The situation of the immigrants in regards to modern contraceptive use is worse although the extent is not adequately documented. The aim of the study was to assess the prevalence and factors associated with modern contraceptives use among married Somali women living in Kampala. Three hundred forty one participants were recruited in a community based, cross sectional survey in Rubaga Division, Kampala. The contraceptive prevalence was $29 \%$ with majority (70\%) using short term contraceptives. The women who were more educated, one who had ever used modern contraceptives, got contraceptive information from the health worker and/or desired spacing of more than two years were more likely to use modern contraceptives. There is need to increase girl child education and male participation in these communities to improve utilization of modern contraceptives. We recommend studies looking at attitudes of this population towards use of long term contraceptives.

\section{Introduction}

Access to family planning (FP) is critical to women and children's health. Globally 303,000 women were estimated to have died from pregnancy and childbirth related complications in 2015 [1]. There is huge gap between the need for and access to contraceptive services leading to the high unmet need for contraceptives [2].

The situation on the unmet need for contraception is even dire among people of Somali decent. Somalia has been undergoing through conflict for more than two decades since the central government collapsed in 1991 . This has led to displacement of people internally as well as immigration with an estimated 810,287 refugees living in different countries [3] . Conflict areas tend to have higher under-five and maternal mortality [4] and high unmet need for contraceptives [5]. This has been attributed to the disproportionate distribution of funds with more emphasis being put on defense and disruption of the health care delivery systems.

Somalia a predominantly Muslim country has one of the highest fertility rates of 6.6 children per woman of reproductive age and modern contraceptive prevalence rate of $1 \%[6,7]$. There is generally a high value of having children in this community and husband approval for the women to use contraceptives is very critical in this population [8].

In refugee settings the factors that are associated with use of contraceptives include access to service delivery points, inadequate knowledge on the different methods, fear of side effects and religious and cultural barriers with adolescent unmarried women most affected [5].
Data on the knowledge, fertility desires and current use of modern contraceptives in married Somali women living in Kampala is lacking. The aim of the study was to determine the prevalence and factors associated with use of modern contraceptive among married Somali women living in Kampala.

\section{Methods}

\section{Study design}

This was community based cross-sectional study done from August to November 2016.

\section{Study site}

The study was carried out in Rubaga division one of the seven Divisions which make up Kampala Capital City. Rubaga division was purposively selected since according to Kampala Capital City Authority (KCCA), majority of Somali people live in Rubaga division. According to UNHCR Registered Somali Refugee Population in Uganda in 2015 were estimated to be 41,014 comprising of $48 \%$ females and 52\% males. By September 2016, about 15,573 of them were in Kampala while 22,474 were staying in Nakivali refugee camp in western Uganda reference [3]. There were no registered households where the Somali live because most of live in informal settlements around Kampala City.

Rubaga Division is located in the western part of the city bordered by Wakiso district to the west and south, Kampala Central Division to the east, and Kawempe Division to the northern part. Administratively, the division is made of 13 parishes - in which there are an equal number of informal settlements. The informal settlements in this part of Kampala are; Busega, Kasubi, Kawaala, Kizito Block Najja II, Kosovo (Bukooza), Lungujja-Kintunzi, Mutundwe-Wabiyinja, Najjanankumbi, Namirembe Bakuli, Namungoona, Nankulabye, Nateete, Ndeeba and Wankulukuku. The geographical extent of Rubaga division occupies a total of 9110 acres of land. Of this, the slum settlements occupy only 1981 acres which accounts for $22 \%$ of the whole division. There are approximately 414,750 people in the informal settlements of Rubaga division.

\section{Study population}

The inclusion criterion was a married Somali woman of reproductive age (18-49 years) who had lived in Uganda for less than 10 years. The potential participants were excluded when they were too ill to answer the questions.

\section{Data collection}

Study participants were approached, screened and recruited into the study after informed written consent. Consecutive sampling of households of Somali families was done. There are no organised settlements in the 
study areas. The households were identified by the research assistants with the help of study participants. Two research assistants who stay in Rubaga Division of Somali origin with the help of some research participants were able to identify the households of interest. Two educative sessions about cervical cancer screening and exclusive breastfeeding were initially held in one of the houses for Somali women who stay in Rubaga by one of the investigators and research assistants, which helped us access more participants.

Quantitative data was obtained using a structured interviewer administered questionnaire. The questionnaire was developed using validated questions from Demographic Health Surveys, background characteristics, reproductive behavior and intentions and contraception [9]. Details on current use of modern contraceptives the type of contraception which was used were collected. The independent variables included age of the woman, religion, level of education of the woman and partner, marital status, occupation. Reproductive history and fertility desire data was collected which included; parity, number of living children, desire for more children, desired future child spacing, contraceptive awareness, source of information about contraceptives, ever use of contraceptives and partner's approval for contraceptive use.

\section{Main outcome variable}

Modern contraceptive use among currently married Somali non-pregnant women of reproductive ages 18-49 years was collected. Women within the ages $18-49$ years were asked if they used any contraceptive to delay or avoid conception. Modern contraceptives methods included pills, female and male sterilization, Intrauterine Device (IUD), injectable, implants, male and female condom, diaphragm, emergency contraception and lactation Amenorrhea Method (LAM).

\section{Quality control}

The data was collected with help of research assistants who were fluent in both English and Somali languages. These were trained for two days by the team on the data collection methods, protocol and consenting process. The research assistants were female with a medical background (Nurse and clinical officer).

The questionnaires were pre-tested on 10 women in Kisenyi before adoption for data collection with a purpose of checking clarity, suitability of questions, identification of repetitions, irrelevance and inconsistence. After pretesting, the questionnaire was revised and further refined during training prior to actual data collection.

\section{Sample size calculations}

The sample size was calculated by adopting the proportion of $26 \%$ which is the modern contraceptive prevalence rate in Uganda (UDHS 2011). A maximum likely error of $5 \%$ with a $95 \%$ confidence interval was used. An allowance of $10 \%$ was estimated for the possible non-response. The sample size was calculated using the Kish Leslie formula (1965) for cross sectional studies which gave a total 341 participants. A total of 381 participants were approached and 40 declined to take part or complete the interview.

\section{Statistical analysis}

Data was entered in Epidata version 3.1 software and exported to STATA 11.0 for analysis. Descriptive analysis was done by calculating mean and standard deviation for continuous and proportion for categorical variables. To identify factors associated with modern contraceptive use, bivariate logistic regression between outcome variable (modern contraceptive use \& non-use) and independent variables (age, education of respondent, education of the

Table 1 Socio Demographic characteristics of the Study participants

\begin{tabular}{|c|c|c|}
\hline Variables & Frequency $(n=341)$ & Percentage (\%) \\
\hline \multicolumn{3}{|l|}{ Age of the participant } \\
\hline Less than 25 years & 66 & 19 \\
\hline $25-29$ years & 103 & 30 \\
\hline 30-34 years & 89 & 26 \\
\hline $35-39$ years & 38 & 11 \\
\hline$>=40$ years & 45 & 13 \\
\hline \multicolumn{3}{|l|}{ Residence status } \\
\hline Refugee & 317 & 93 \\
\hline Resident & 24 & 7 \\
\hline \multicolumn{3}{|l|}{ Length of stay in Uganda } \\
\hline less than 1 year & 133 & 39 \\
\hline 1 to 5 years & 160 & 47 \\
\hline $6-<10$ yrs & 48 & 14 \\
\hline \multicolumn{3}{|l|}{ Women's education status } \\
\hline Informal/none & 136 & 40 \\
\hline Primary & 49 & 14 \\
\hline Secondary & 94 & 28 \\
\hline Tertiary & 62 & 18 \\
\hline \multicolumn{3}{|l|}{ Employment status } \\
\hline Housewife & 249 & 73 \\
\hline Informal employment & 48 & 14 \\
\hline Student & 29 & 9 \\
\hline Professional/others & 15 & 4 \\
\hline \multicolumn{3}{|l|}{ Husband education status } \\
\hline Informal & 137 & 40 \\
\hline Primary & 10 & 3 \\
\hline Secondary & 72 & 21 \\
\hline Tertiary & 122 & 36 \\
\hline
\end{tabular}


husband, employment status, exposure to family planning messages, husband approval) was carried out. Crude odds ratio (OR) and their 95\% confidence intervals (CI) were calculated. Variables with $p$-value $<0.02$ or which are biologically important were selected for multivariable logistic regression analysis. The final multivariable logistic regressions was performed to assess the independent effects of individual factors by controlling potential confounders and adjusted OR (AOR) with their 95\% CI was computed using a backward elimination method.

\section{Results}

The majority of the enrolled participants were refugees $317 / 341$ (93\%), of which $133 / 317$ (39\%) had lived in Uganda for less than one year. Majority 249/341 (73\%) were housewives and 136/341 (40\%) did not have any formal education. The details of the demographics characteristics are shown in Table 1.

\section{Reproductive history and fertility intentions of the study participants}

Almost half of participants 158/341 (46\%) were less than 20 years at marriage and 164/305 (45\%) had five or more living children. Nearly all participants 325/341 (94\%) desired to have more than five children (average of 9) but with a desire for spacing of two or more years 208/305 (69\%). Other details of fertility intentions are shown in Table 2.

\section{Awareness and ever use of modern contraceptives}

The majority of participants 273/314 (80\%) had ever heard about modern contraceptives.

Table 2 Reproductive history and fertility intentions of study participants

\begin{tabular}{|c|c|c|}
\hline Variables & Frequency $(n=341)$ & Percentage (\%) \\
\hline \multicolumn{3}{|l|}{ Age at marriage } \\
\hline Less than 20 years & 158 & 46 \\
\hline 20 to 25 years & 157 & 46 \\
\hline 26 years and more & 26 & 7 \\
\hline \multicolumn{3}{|l|}{ Have you ever got pregnant } \\
\hline Yes & 305 & 89 \\
\hline No & 36 & 11 \\
\hline \multicolumn{3}{|l|}{ Parity } \\
\hline 0 & 36 & 11 \\
\hline Less than 4 & 123 & 36 \\
\hline 4 or more & 182 & 53 \\
\hline${ }^{a}$ Current living children & 305 & \\
\hline 1 child & 30 & 11 \\
\hline $2-4$ children & 111 & 44 \\
\hline$>=5$ children & 164 & 45 \\
\hline Space between children & 286 & \\
\hline Less than 2 years & 157 & 55 \\
\hline 2 years & 103 & 35 \\
\hline More than 2 years & 26 & 10 \\
\hline Desired number of children by woman & 340 & \\
\hline$<5$ & 15 & 4 \\
\hline$>=5$ & 325 & 96 \\
\hline Desired number of children by husband & 341 & \\
\hline Same number & 62 & 18 \\
\hline More children & 120 & 35 \\
\hline Less children/Don't Know & 159 & 47 \\
\hline 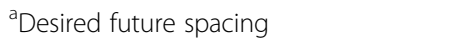 & 305 & \\
\hline$<2$ years & 97 & 31 \\
\hline 2 years & 160 & 53 \\
\hline$>2$ years & 48 & 16 \\
\hline
\end{tabular}

${ }^{\mathrm{a}}$ Only women with children included 
More than half of them 138/273 (51\%) had heard about modern contraceptives from a health worker, while 73/ 273 (27\%) from a friend. Among women who had ever heard about modern contraceptives, 192/273 (70\%) had ever used at least one of the modern contraceptives. Short acting contraceptives like oral contraceptive pills 83/192 (43\%) and condoms 58/192 (30\%) were the most commonly ever used contraceptives. More than half 150/341 (55\%) of the women had ever discussed use of modern contraceptives with their husbands but only 124/273 (46\%) of them got their husbands approval to start use of modern contraceptives yet for 255/273 (94\%) of the women felt that they can only proceed to use after the approval. Details on awareness and ever use of modern contraceptives are shown in Table 3.

\section{Prevalence of modern contraceptive use among married Somali women in Kampala}

The study found that 100/341 (29\%) of married Somali women living in Kampala were using modern contraceptives at 95\% confidence interval (24.6-34.6). More than half of these were short term contraceptives; 51/100 (51\%) were using oral pills and 15/100 (15\%) condoms. Eight participants declined to respond to the reason why they chose the method they were using, lack of side effects 35/92 (38\%) and availability 14/92 (15\%) were the main reasons for choosing that method. Details on the current methods used by the study participants are shown in Table 4.

\section{Actors associated with current use of modern contraceptives among Somali women living in Kampala} Majority 98/100 (98\%) of the participants who were using modern contraceptives had ever used previously. The factor of ever use of modern contraceptives was not included in the multivariate model. After adjusting for other factors, the following factors were found to be associated with current use of modern contraceptives; the participants who had attained tertiary education had four times higher odds of using modern contraceptives. The participants who desired spacing for more than two years, those whose husbands desired more children than

Table 3 Awareness and ever use of modern contraceptives

\begin{tabular}{|c|c|c|}
\hline Variables & Frequency $(n=341)$ & Percentage (\%) \\
\hline \multicolumn{3}{|l|}{ Women who are aware about modern contraceptives } \\
\hline Yes & 273 & 80 \\
\hline No & 68 & 20 \\
\hline \multicolumn{3}{|l|}{ Source of information about contraceptives } \\
\hline Heath worker & 138 & 51 \\
\hline Media & 13 & 5 \\
\hline Newspaper & 4 & 1 \\
\hline Television & 23 & 8 \\
\hline Radio & 10 & 4 \\
\hline Internet & 23 & 8 \\
\hline Friend & 73 & 27 \\
\hline Family member & 14 & 5 \\
\hline Believes husband's approval is a must before use & 255 & 94 \\
\hline Had ever discussed contraceptives with their husbands & 150 & 55 \\
\hline Got husband approval & 124 & 46 \\
\hline \multicolumn{3}{|l|}{ Ever used modern contraceptives } \\
\hline Yes & 192 & 56 \\
\hline No & 149 & 44 \\
\hline \multicolumn{3}{|l|}{ Methods used *192 } \\
\hline condom & 58 & 30 \\
\hline Oral pills & 83 & 43 \\
\hline Injectables & 26 & 14 \\
\hline implants & 12 & 6 \\
\hline Intrauterine Device & 6 & 3 \\
\hline Vaginal rings & 7 & 4 \\
\hline
\end{tabular}


Table 4 Current use of modern contraceptives among married Somali women in Kampala

\begin{tabular}{|c|c|c|}
\hline Variables & Frequency $(n=100)$ & Percentage (\%) \\
\hline \multicolumn{3}{|c|}{ Contraceptive method used currently } \\
\hline Condom & 15 & 15 \\
\hline Oral pills & 51 & 51 \\
\hline Injectables & 15 & 15 \\
\hline Implants & 7 & 7 \\
\hline Intrauterine Device & 4 & 4 \\
\hline Vaginal rings & 4 & 4 \\
\hline Combination of methods & 2 & 2 \\
\hline Others & 2 & 2 \\
\hline \multicolumn{3}{|c|}{ 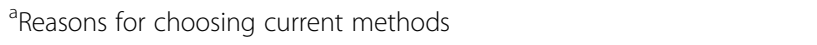 } \\
\hline Available & 14 & 15 \\
\hline User controlled & 12 & 13 \\
\hline No side effects & 35 & 38 \\
\hline Doctor's advice & 10 & 11 \\
\hline Cheap & 8 & 9 \\
\hline Combination & 2 & 2 \\
\hline Others & 11 & 12 \\
\hline \multicolumn{3}{|l|}{ Side effects } \\
\hline Bleeding & 19 & 19 \\
\hline Pain & 36 & 36 \\
\hline Abnormal blood clot & 2 & 2 \\
\hline Delay fertility return & 3 & 3 \\
\hline Unwanted weight gain & 10 & 10 \\
\hline Others & 19 & 19 \\
\hline
\end{tabular}

as people didn't respond

them and where the source of information on modern contraceptives was health worker were more likely to use modern contraceptives after multivariate analysis. Details on the factors that influenced current use of modern contraceptives after multivariate analysis are shown in Table 5.

\section{Discussion}

This study looked at the factors associated with modern contraceptive use among married Somali women living in Kampala. Previous use of modern contraceptives, having attained tertiary education, desire for child spacing of more than two years, husband desire for more children and those who got the information of modern contraceptives from the health worker were more likely to use modern contraceptives. The prevalence of modern contraceptive use among married Somali women living in Kampala was found to be $29 \%$ that is higher than prevalence of modern contraceptive use in Somalia which is $1 \%$ [7], but lower than the current prevalence of the country (Uganda) which is 39\% [10]. Studies have demonstrated that immigrant Married Somali women generally have higher modern contraceptive rates than their counterparts living in Somalia. Living in a new community may greatly improve the decision making and discussion about contraceptives amongst the couples [11] and yet in some cases the general practitioners are less likely to discuss contraceptive with the refugee and migrant women especially of African descent than the natives [12]. Studies have demonstrated differences in modern contraceptive prevalence in immigrant population, with some showing a lower prevalence than resident women [13] and others having a comparable contraceptive prevalence rates $[11,14]$. The differences can be explained by the different populations with those with a very high prevalence in hospital based studies and there are differences in the definition of contraceptive prevalence with some studies including traditional contraceptive methods and others not.

A significant proportion (40\%) of the participants did not have any formal education or had attained only primary education (14\%). The participants who had attained tertiary education were four times higher odds of using modern contraceptives than those who had no formal education after controlling for confounders. This finding is consistent with other studies showing that educated women were more likely to use modern contraceptives than their less educated counterparts [15-17]. Formal education is likely to influence the attitudes, knowledge and access to health services. Knowledge and access are very important in determining those who will use the modern contraceptives.

Nearly three quarters of the women desired child spacing of two or more years though only $29 \%$ were currently using, the remaining $39 \%$ may have had unmet need for contraception. The women who desired spacing of more than two years had higher odds of using modern contraceptives. A study done in Uganda showed that women with future desire for children, would like to have two or more years of spacing [18]. Potential contributing factors to the high unmet need for contraceptives include failure to get husband's approval, lack of awareness about modern contraceptives, or fear of side effects. A systematic review of studies done in SubSaharan Africa, male partner approval was found to negatively affect contraceptive use [19]. Another possible explanation can be absence of husband, where the couple may not stay together sometimes because of refugee status. Majority of participants had ever heard about modern contraceptives and yet only half of these got the information from a health worker. Participants who had got the information of modern contraceptive form a health worker were independently more likely to use modern contraceptives. In a study where majority of the 
Table 5 Factors associated with current use of modern contraceptive after multivariate analysis

\begin{tabular}{|c|c|c|c|}
\hline Variables & Adjusted OR & 95\% Confidence Interval & $P$-value \\
\hline \multicolumn{4}{|l|}{ Age of the participant } \\
\hline Less than 20 years & 1 & & \\
\hline 20-24 years & 0.895 & $0.2-4.2$ & 0.888 \\
\hline $25-29$ years & 1.594 & $0.5-4.9$ & 0.417 \\
\hline 30-34 years & 0.888 & $0.3-2.5$ & 0.823 \\
\hline $35-39$ years & 1.143 & $0.3-3.8$ & 0.827 \\
\hline$>=40$ years & 1 & & \\
\hline \multicolumn{4}{|l|}{ Level of education } \\
\hline Informal & 1 & & \\
\hline Primary & 0.867 & $0.3-2.4$ & 0.781 \\
\hline Secondary & 1.167 & $0.5-2.6$ & 0.706 \\
\hline Tertiary & 4.342 & $1.7-10.8$ & $0.002 *$ \\
\hline \multicolumn{4}{|l|}{ Parity } \\
\hline 0 & 1 & & \\
\hline 1 & 1.995 & $0.2-18.9$ & 0.548 \\
\hline 2 & 1.934 & $0.2-18.0$ & 0.562 \\
\hline 3 or more & 1 & & \\
\hline \multicolumn{4}{|l|}{ Space between children } \\
\hline Less than 2 years & 1 & & \\
\hline 2 years & 1.201 & $0.6-2.4$ & 0.608 \\
\hline More than 2 years & 3.240 & $1.0-10.1$ & $0.043^{*}$ \\
\hline \multicolumn{4}{|c|}{ Desirable number of children by husband } \\
\hline Same number as woman & 1 & & \\
\hline More children than woman & 2.748 & $1.1-6.9$ & $0.032 *$ \\
\hline Less children/Don't Know & 2.143 & $0.8-5.7$ & 0.129 \\
\hline \multicolumn{4}{|c|}{ Source of information about contraceptives } \\
\hline \multicolumn{4}{|l|}{ Heath worker } \\
\hline Yes & 3.003 & $1.6-5.8$ & $0.001^{*}$ \\
\hline No & 1 & & \\
\hline \multicolumn{4}{|l|}{ Desired future spacing } \\
\hline$<2$ years & 1 & & \\
\hline 2 years & 2.045 & $0.9-5.0$ & 0.075 \\
\hline$>2$ years & 3.511 & $1.3-9.8$ & $0.016^{*}$ \\
\hline
\end{tabular}

${ }^{*} P$ value less the 0.005

participants got information from television only attitude of the participants and religious influence affected use of modern contraceptives [20]. Information from a health worker is likely to be accurate and gives an opportunity to address any misunderstanding. Participants who get the information from friends on other hand are likely to get distorted and incomplete information that hinders them from using modern contraceptives.

Women who had ever used any modern contraceptive were more likely to currently use contraceptives in this population. The main reason for choosing the contraceptives was the lack of side effects. It's likely ever use of contraceptives dispelled all the different myths and these had realised the benefits of contraceptive use.

\section{Strengths and limitations}

The main strength of this study was that, being community based, it could reflect the actual experience of the married Somali women during the study period. This looks at a special group of refugees not living in camps. 
It's a big sample size which can be generalizable to this special group. One limitation of this study was the use of consecutive sampling, as well as snow ball recruiting to identify potential participants. This may affect the representativeness of the interviewed population, although the large number of participants should help to limit his concern. This was done to enable us reach as many of the potential participants who normally stay at home. This is a true representation of this community since these tend to live in the same neighbourhood.

\section{Conclusion}

In this largely refugee married Somali population living in Kampala, the modern contraceptive prevalence among married women was $29 \%$ with majority using short term contraceptives. The more educated women, those who had ever used contraceptives and those who desired spacing the children for more than two years had higher odds of using modern contraceptives. These women desired spacing the pregnancy for more than two years but were using short term contraceptive methods. The participants desired to have an average of nine children and considered that the approval of the husband was crucial before use of contraceptives.

\section{Implications of the study}

Understanding the factors that influence uptake of modern contraceptives will help policy makers to engage Somali community leaders on how to make tailored information that is useful in increasing contraceptive awareness among people of Somali decent. This in turn will improve contraceptive uptake for this special group. Further research looking at the reasons underlying the choice of contraceptives and attitudes towards use of long term contraceptives is recommended in this population. Studies investigating ways of increasing male participation in use of modern contraceptives in the Somali community need to be done.

\section{Abbreviations}

SOMREC: School Of Medicine Research and Ethics Committee; CPR: Contraceptive prevalence rate; KCCA: Kampala Capital City Authority; UNHCR: United Nations High Commissioner for Refugees

\section{Acknowledgements}

We are grateful to Dr. Kazibwe Lawrence and Prof. Dan Kaye who gave some ideas at conception. All the research assistants and the women who agreed to take part in this study are highly appreciated. Doreen Asaba, the statistician on the study for the time and dedication to this work.

\section{Declarations}

Authors declare no conflict of interest.

\section{Authors' contributions}

MA, prepared the proposal and conducted the study, drafted the first manuscript. NF supervised every part of the study, data analysis and provided guidance at each level. KO was key in the conception of the idea and interpretation and revision of the final manuscript. All authors read and approved the final manuscript.

\section{Funding}

The study was funded by the investigators.

\section{Availability of data and materials}

The datasets used and/or analysed during the current study are available from the corresponding author on request.

\section{Ethics approval and consent to participate}

Ethical approval was obtained from the Makerere University College of Health Sciences, School of Medicine Research and Ethics committee.

Institutional consent to conduct the study was obtained from the Local Councils administration of Rubaga Division. Information about the study was explained to participants' and informed written consents obtained from each woman (18-49 years old). Participation was voluntary and participants had the right to withdraw from the study at any time.

\section{Competing interests}

The authors declare that they have no competing interests.

Received: 1 May 2018 Accepted: 14 May 2020

Published online: 24 May 2020

\section{References}

1. Ozimek JA, Kilpatrick SJ. Maternal mortality in the twenty-first century. Obstet Gynecol Clin N Am. 2018;45(2):175-86.

2. Bongaarts J, Bruce J. The causes of unmet need for contraception and the social content of services. Stud Fam Plan. 1995;26(2):57-75.

3. UNHCR, Horn of Africa Situation https://data2.unhcr.org/en/situations/horn, 2019. Situations (Acessed 5th July 2019).

4. O'Hare BA, Southall DP. First do no harm: the impact of recent armed conflict on maternal and child health in sub-Saharan Africa. J R Soc Med. 2007;100(12):564-70.

5. Mihoko Tanabe AM, Bhandari P, Cornier N, Doraiswamy S, Krause S. Family planning in refugee settings: findings and actions from a multi-country study. Confl Heal. 2017;11(9):79-86.

6. Susuman AS, et al. High infant mortality rate, high total fertility rate and very low female literacy in selected African countries. Scand J Public Health. 2016;44(1):2-5.

7. Bureau, P.R., 2016 World Population Data Sheet. https://www.prb.org/wpcontent/uploads/2016/08/prb-wpds2016-web-2016.pdf, 2016. Acessed 15th January 2016.

8. Joesoef MR, Baughman AL, Utomo B. Husband's approval of contraceptive use in metropolitan Indonesia: program implications. Stud Fam Plan. 1988; 19(3):162-8.

9. USAID, Demographic Health Surveys https://dhsprogram.com/what-we-do/ survey-types/dhs-questionnaires.cfm, 2016. Accessed 17th January 2016.

10. Statistics, U.B.O., Uganda Demographic and Health Survey 2016 https:// www.ubos.org/onlinefiles/uploads/ubos/pdf\%20documents/Uganda_DHS_2 016 KIR.pdf, 2016.

11. Cox CM, et al. Decision making and communication about child spacing among Somali couples in Minnesota. Perspect Sex Reprod Health. 2019; 51(2):63-9.

12. Raben $L A D$, van den Muijsenbergh M. Inequity in contraceptive care between refugees and other migrant women?: a retrospective study in Dutch general practice. Fam Pract. 2018;35(4):468-74.

13. Degni F, Koivusilta L, Ojanlatva A. Attitudes towards and perceptions about contraceptive use among married refugee women of Somali descent living in Finland. Eur J Contracept Reprod Health Care. 2006;11(3):190-6.

14. Aptekman $\mathrm{M}$, et al. Unmet contraceptive needs among refugees. Can Fam Physician. 2014;60(12):e613-9.

15. Kidayi, P.L., Msuya, S., Todd, J., Mtuya, C.C., Mtuy, T. and Mahande, M.J, Determinants of Modern Contraceptive Use among Women of Reproductive Age in Tanzania: Evidence from Tanzania Demographic and Health Survey Data. Adv Sex Med, 5, , 2015. 5: p. 43-52.

16. Aviisah PA, et al. Modern contraceptive use among women of reproductive age in Ghana: analysis of the 2003-2014 Ghana demographic and health surveys. BMC Womens Health. 2018;18(1):141.

17. Rutaremwa $\mathrm{G}$, et al. Predictors of modern contraceptive use during the postpartum period among women in Uganda: a population-based cross sectional study. BMC Public Health. 2015;15:262. 
18. Gutin SA, et al. Fertility desires and intentions among HIV-positive women during the post-natal period in Uganda. Afr J Reprod Health. 2014;18(3):67-77.

19. Blackstone SR, Nwaozuru U, Iwelunmor J. Factors influencing contraceptive use in sub-Saharan Africa: a systematic review. Int Q Community Health Educ. 2017;37(2):79-91.

20. Beson P, Appiah R, Adomah-Afari A. Modern contraceptive use among reproductive-aged women in Ghana: prevalence, predictors, and policy implications. BMC Womens Health. 2018;18(1):157.

\section{Publisher's Note}

Springer Nature remains neutral with regard to jurisdictional claims in published maps and institutional affiliations.

Ready to submit your research? Choose BMC and benefit from:

- fast, convenient online submission

- thorough peer review by experienced researchers in your field

- rapid publication on acceptance

- support for research data, including large and complex data types

- gold Open Access which fosters wider collaboration and increased citations

- maximum visibility for your research: over $100 \mathrm{M}$ website views per year

At $\mathrm{BMC}$, research is always in progress.

Learn more biomedcentral.com/submissions 